\title{
PELATIHAN SENAM REMATIK UNTUK MENURUNANKAN NYERI PADA PENDERITA RHEUMATOID ARTHRITIS DIDESA PERIGI KECAMATAN PULAU PINANG KABUPATEN LAHAT TAHUN 2020
}

\author{
Yeni Elviani'1), Zuraidah S. ${ }^{2)}$, Wahyu Dwi Ari Wlbowo2) \\ ${ }^{1)}$ Program Studi D-III Keperawatan Lahat, Politeknik Kesehatan Kemenkes Palembang, Palembang, Sumatera \\ Selatan, Indonesia \\ ${ }^{2}$ Program Studi D-III Keperawatan Lubuklinggau, Politeknik Kesehatan Kemenkes Pakembang, Palembang \\ Sumatera Selatan
}

Corresponding author: Wahyu Dwi Ari Wibowo

E-mail : wahyudwi74@poltekkespalembang.ac.id

\section{Diterima 01 November 2021, Disetujui 05 November 2021}

\begin{abstract}
ABSTRAK
Rheumatoid arthritis (RA) merupakan permasalahan sistem muskuloskeletal yang paling banyak terjadi di seluruh dunia, dampak dari RA menyebabkan gangguan kenyamanan, nyeri, keterbatasan mobilitas sampai dengan resiko kecacatan dan kelumpuhan. Program aktifitas fisik yang efektif sangat direkomendasikan bagi penderita RA adalah senam rematik yang sudah terbukti mampu mengurangi skala nyeri bagi para penderita RA. Berdasarkan studi pendahuluan ternyata penderita RA belum mengetahui cara melakukan senam rematik untuk mengurangi nyeri sendi. Sehingga pengenalan dan pemeberian senam rematik bagi para penderita RA wilayah kerja Puskesmas Pulau Pinang perlu untuk dilakukan sebagai program aktifitas fisik yang diharapkan mampu menurungkan skala nyeri bagi para penderita RA. Metode yang dilakukkan adalah melakukan studi pendahuluan, bekerjasama dengan tenaga kesehatan, tokoh masyarakat dan kader yang ada di wilayah Puskesmas Pulau Pinang, pelaksanaan kegiatan dengan memberikan pelatihan dengan cara menonton video dan praktek secara langsung senam rematik, selanjutnya dlakukan pemantaun sebelum dan sesudah intervensi dengan menggunakan lembar observasi Numerical Rating scale (NRS). Hasilnya setelah diberikan senam rematik selama 1 bulan, dengan $1 x$ kegiatan setiap minggu dengan durasi 8 menit, terjadi penurunan skala nyeri 15 orang peserta yang mengalami nyeri sedang menjadi nyeri ringan. Senam rematik mampu mempengaruhi kerja cerebral cortex meliputi aspek kognitif maupun emosi, sehingga dapat memberikan persepsi positif dan relaksasi, yang berdampak pada perasaan bahagia dan mengurangi nyeri.
\end{abstract}

Kata Kunci : senam rematik; rheumatoid arthritis; nyeri; komunitas.

\begin{abstract}
Rheumatoid arthritis (RA) is the most common musculoskeletal system problem worldwide, the impact of RA causing discomfort, pain, limited mobility, and the risk of disability and paralysis. An effective physical activity program highly recommended for RA sufferers is rheumatic gymnastics, which has been proven to reduce pain scales for RA sufferers. Based on preliminary studies, RA patients do not know how to do rheumatic gymnastics to reduce joint pain. The introduction and intervention of rheumatic gymnastics for patients with RA in the Pulau Pinang Health Center need to be carried out as a physical activity program to reducing the pain scale for the sufferer of RA. The method used is conducting a preliminary study, collaboration with health workers, community leaders, and cadres in the Pulau Pinang Health Center area, implementing activities by providing training by watching videos and practicing rheumatic gymnastic, and then monitoring before and after the intervention using Numerical Rating scale (NRS) observation. The result was that after being given rheumatic exercise for one month, with one activity per week in 8 minutes duration, there was a decrease in the pain scale of 15 participants who experienced moderate pain to mild pain. Rheumatic gymnastics can affect the work of the cerebral cortex, including cognitive and emotional aspects, providing positive perceptions and relaxation, which has an impact on feelings of happiness and reduces pain.
\end{abstract}

Keywords: rheumatic gymnastics; rheumatoid arthritis; pain; community.

\section{PENDAHULUAN}

Rheumatoid arthritis (RA) merupakan permasalahan sistem muskuloskeletal yang paling banyak terjadi di seluruh dunia, menurut studi Global Burden of Diseases, Injuries, and Risk Factors (GBD) tahun 2017 ada 20 juta 
orang di seluruh dunia hidup dengan RA, dengan lebih dari satu juta kasus baru didiagnosis setiap tahun, dan berada pada angka 14,9 kasus per 100.000 orang (Safiri et al., 2019). Di Indonesia prevalensi penyakit RA berdasarkan diagnosis dokter yaitu berkisar pada angka $7.30 \%$, sedangkan berdasarkan karakteristik umur penderita RA berada pada umur diatas 60 tahun yaitu sebesar 18,95\% (RISKESDAS, 2018).

Dampak dari RA menyebabkan gangguan kenyamanan, nyeri dan keterbatasan mobilitas fisik bagi para penderitanya, hingga beresiko menyebabkan kecacatan dan kelumpuhan (Silaban, 2016). Intervensi dari nyeri yang diakibatkan oleh masalah RA dapat dilakukan untuk mengurangi nyeri dengan cara farmakalogis dan non-farmakologis, akan tetapi resiko dari obat-obatan dapat memberikan efek yang kurang baik bagi kesehatan karena mengingat tidak ada obat yang dapat menyembuhkan RA intervsni uang diberikan sebagai tindakan untuk mengurangi gejala nyeri, dan peradangan, sehingga aktivitas fisik pergerakan sendi sangat dianjurkan untuk meminimalkan kontraktur dan mengatasi penurunan fungsional sendi akibat nyeri sendi yang muncul (Sitinjak et. al., 2016).

Berdasarkan penelitian (Afnuhazi, 2018) pemberian aktivitas olahraga fisik yang di anjurkan bagi lansia dengan RA adalah senam rematik, karena terbukti senam rematik yang dilakukan dalam kurun waktu 8 menit, 1 minggu sekali, dalam waktu sebulan mampu menurunan skala nyeri persendian yang dialami lansia. Tidak hanya berpengaruh terhadap skala nyeri yang dialami, akan tetapi senam rematik juga bermanfaat untuk meningkatkan kemandirian lansia dalam melakukan Activity Daily Living (ADL) (Susilowati, 2016). Senam rematik berfokus pada mempertahankan lingkup ruang gerak sendi secara maksimal. Salah satu tujuannya adalah mengurangi nyeri sendi dan menjaga keseimbangan jasmani (HERI KUSWANTO, 2014).

Anggapan masyarakat terhadap RA sebagai radang sendi biasa yang dialami lansia menyebabkan keterlambat melakukan pengobatan, sehingga factor tingkat pengetahuan dan kemampuan dalam penatalaksaan sudatu penyakit dangat mempengaruhi perilaku penatalaksanaan kesehatan, khususnya masalah rheumatoid (Padila, 2013). Berdasarkan kajian studi pendahuluan yang pada 10 penderita RA wilayah kerja Puskesmas Pulau Pinang, di dapatkan data bahwa 7 dari 10 pendirita mengalami nyeri sedang yang di akibatkan oleh peradangan sendi, dan 8 dari 10 orang tersebut belum mengetahui cara melakukan senam rematik untuk mengurangi nyeri sendi yang di alami. Dari data diatas kami sangat tertarik untuk melakukkan pengabdian masyarakat dengan cara memberikan pelatihan senam rematik kepada pendirita $R A$, sebagai salah satu intervensi penatalaksaan nonfarmakalogis untuk mengurangi nyeri bagi penderita RA.

\section{METODE}

Kegiatan pengabdian kepada masyarakat dilaksanakan di wilayah kerja Puskesmas Pulau Pinang, tepatnya di Desa Perigi, Kecamatan Pulau Pinang, Kabupaten Lahat, pada tanggal 30 September - 30 November 2020, dengan sasaran kegiatan PKM adalah penderita RA di wilayah tersebut. Kegiatan PKM ini dilaksanakan oleh dosen dan mahasiswa DIII Keperawatan Lahat.

Pada kegiatan ini dosen secara bergantian memimpin kegiatan senam rematik yang dilakukan selama 1 minggu sekali, selama 1 bulan, sedangkan untuk mahasiswa bertugas membantu menyiapkan alat dan bahan yang digunakan untuk melakukan kegiatan senam, pengisian daftar hadir, dan pemberian leaflet dan konsumsi kepada peserta yang hadir. Kegiatan ini dilakukan dengan cara menonton video dan praktik senam rematik secara langsung kepada peserta.

Tahapan pelaksanaan kegiatan difokuskan pada 3 kegiatan yaitu:

1. Tahap pertama merupakan tahap perencanaan kegiatan yang akan dilakukan. Proses perencanaan meliputi survey lapangan, studi pendahuluan, dan rapat koordinasi dengan mitra dan petugas kesehatan meliputi identifikasi kebutuhan masalah, karakteristik mitra, tempat pelatihan, kesepakatan tempat dan waktu pelatihan yang disusun bersama dengan perangkat desa, tokoh masyarakat dan kader yang ada di wilayah kerja Puskesmas Pulau Pinang.

2. Tahap kedua merupakan tahap pelaksanaan kegiatan pengabdian masyarakat yang dilakukan oleh tim yang terlibat dalam penyuluhan dan pelatihan yaitu dosen, mahasiswa, petugas kesehatan dan kader kesehatan.

3. Tahap ke tiga dilakukan monitoring dan evaluasi kegiatan. Proses ini dilakukan sendiri oleh Tim Pengabdian Masyarakat kepada peserta pelatihan. Bentuk monitoring yang dilakukan adalah penilaian skala nyeri sebelum dan sesudah dilakukan intervensi dengan menggunakan lembar observasi Numerical Rating scale (NRS). 
HASIL DAN PEMBAHASAN

Tabel 1. Karakteristik Peserta Senam

Rematik

\begin{tabular}{lcc}
\hline \multicolumn{1}{c}{ Karetristik } & $\begin{array}{l}\text { Frekuensi } \\
(\mathbf{n})\end{array}$ & $\begin{array}{l}\text { Presentase } \\
(\%)\end{array}$ \\
\hline Jenis Kelamin & & \\
\hline Perempuan & 31 & 88,5 \\
\hline Laki-laki & 4 & 11,5 \\
\hline Umur & & 11.4 \\
\hline 45-59 Tahun & 4 & 71.4 \\
\hline 60-74 Tahun & 25 & 17.1 \\
\hline $\begin{array}{l}\text { Lebih dari } 74 \\
\text { Tahun }\end{array}$ & 6 & \\
\hline $\begin{array}{l}\text { Riwayat } \\
\text { Monopouse } \\
\text { bagi } \\
\text { Perempuan }\end{array}$ & & \\
\hline $\begin{array}{l}\text { Belum } \\
\text { Menopause }\end{array}$ & 2 & 6.4 \\
\hline $\begin{array}{l}\text { Sudah } \\
\text { Menopause }\end{array}$ & 29 & 93.5 \\
\hline
\end{tabular}

Tabel 1 menunjukkan jenis kelamin sebagian besar peserta adalah perempuan sebanyak 31 orang $(85 \%)$, dari 31 orang wanita tersebut 29 orang $(93.5 \%)$ sudah mengalami menopause. Peserta senam rematik di atas juga merupakan penderita RA, dimana dari hasil tersebut di dominasi oleh perempuan, Menurut para ahli (Intermountein Healthcare, 2016) wanita mendapatkan penyakit autoimun dalam jumlah yang jauh lebih besar daripada pria, diperkirakan bahwa sistem kekebalan wanita lebih kuat dan lebih reaktif, akan tetapi dampaknya seiring berjalan nya waktu hormon tadi menjadi risiko kemungkinan peningkatan RA. Didukung oleh penelitian (Siebert et al., 2016) faktor lainnya dapat disebabkan oleh seiring bertambahnya usai perempuan akan mengalami perubahan hormon dan menopause,hal ini diperberat apabila menopause terjadi sebelum perempuan berusia 50 tahun. Kejadian RA dua sampai tiga lebih berisiko di alami wanita (CDCV, 2020).

Tabel 1 juga menunjukan umur terbanyak peserta pada usia 60-74 tahun sebanyak $71.4 \%$ atau 25 peserta. Hal ini sejalan dengan pernyataan (CDCV, 2020) yang menyatakan "Pada dasarnya RA mungkin terjadi bahkan di usia remaja, akan tetapi onset tertinggi akan berada di antara orang dewasa dengan usia enam puluhan". Menurut Lin, (2017) semakin bertambahnya usia seseorang akan mengalami imunoesensi secara bertahap yang dapat mengakibatkan peradangan kronis serta kerusakan jaringan.
Tabel 2. Skala Nyeri Peserta Sebelum Di Berikan Intervensi Senam Rematik

\begin{tabular}{c|c|c}
\hline \multicolumn{3}{c}{ SEBELUM SENAM REMATIK } \\
Tingkat Nyeri & Frekuensi & Presentase \\
\hline $\begin{array}{c}\text { Nyeri sedang (4- } \\
\text { 6) }\end{array}$ & 26 & 74.2 \\
\hline $\begin{array}{c}\text { Nyeri Ringan (1- } \\
\text { 3) }\end{array}$ & 9 & 25.7 \\
\hline Total & 35 & 100 \\
\hline
\end{tabular}

Tabel 2 menunjukkan skala nyeri peserta sebelum diberikan intervensi senam rematik, didapatkan data bahwa, ada 26 orang peserta atau $74.2 \%$, mengalami nyeri sedang, sedangkan 9 orang peserta atau $25.7 \%$ mengalami nyeri ringan. Salah satu dan dan gejala RA adalah nyeri yang dialami pada lebih dari satu sendi, Kekakuan pada lebih dari satu sendi, kelelahan, kelemahan, bahkan sampai dengan kehilangan berat badan (CDCV, 2020). Nyeri tekan dan bengkak di lebih dari satu sendi muncul akibat dari beberapa mekanisme, yang melibatkan peradangan, pemrosesan nyeri perifer dan sentral dengan perkembangan penyakit, dan terjadinya perubuhan struktur dalam sendi (Walsh \& McWilliams, 2014). RA merupakan sebuah inflamasi kronik mengenai sendi-sendi sinovial, sehingga dapat menimbulkan gangguan nyeri pada penderita rematik (Siahaan et al., 2017).

Tabel 3. Skala Nyeri Peserta Setelah Di

Berikan Intervensi Senam Rematik

SETELAH SENAM REMATIK

\begin{tabular}{c|c|c}
\multicolumn{3}{c}{ SETELAH SENAM REMATIK } \\
Tingkat Nyeri & Frekuensi & Presentase \\
\hline $\begin{array}{c}\text { Nyeri sedang (4- } \\
\text { 6) }\end{array}$ & 11 & 31.4 \\
\hline $\begin{array}{c}\text { Nyeri Ringan (1- } \\
\text { 3) }\end{array}$ & 24 & 68.5 \\
\hline Total & 35 & 100 \\
\hline
\end{tabular}

Tabel 3 menunjukkan skala nyeri peserta setelah diberikan intervensi senam rematik, didapatkan data bahwa, terdapat penurunan jumlah penderita RA dengan nyeri sedang menjadi 11 orang peserta atau $31.4 \%$, sedangkan peserta yang mengalami RA dengan nyeri ringan meningkat menjadi 24 orang peserta atau sebanyak $68.5 \%$. dari kegiatan ini setelah diberikan intervensi senam rematik selama 1 bulan, dengan intesitas 1 minggu sekali selama 8 menit, kita bisa melihat bahwa terjadi penurunan skala nyeri 15 orang peserta yang mengalami nyeri sedang menjadi nyeri ringan. Hal ini sejalan dengan penelitian (Arfitasari, 2020) yang melakukan penelitian pada 30 orang penderita RA di Desa Mancasan, Kecamatan Baki, kabupaten Sukoharjo, menunjukan hasil yang sama bahwa senam rematik terbukti terhadap penurunan nyeri penderita RA. Senam rematik mempengaruhi 
kerja cerebral cortex meliputi aspek kognitif maupun emosi, sehingga dapat memberikan persepsi positif dan relaksasi, secara tidak langsung membantu dalam memelihara keseimbangan homeostasis tubuh (Afnuhazi, 2018).

Senam remanatik merupakan salah satu aktifitas fisik, menurut Centers for Disease Control and Prevention (CDCV) pada tahun 2020 program aktivitas fisik yang efektif sangat durekomendasikan bagi penderita RA semua kelompok umur, karena program aktivitas fisik dapat membantu mengurangi rasa sakit dan kecacatan, meningkatkan suasana hati dan kemampuan untuk bergerak. Senam rematik juga dampak psikologis, yaitu timbulnya perasaan santai, meningkatkan perasaan senang dikarenakan pada saat senam berlangsung kelenjar pituari menambah produksi beta endorphin yang berfungsi untuk menimbulkan perasaan bahagia, mengurangi kecemasan, dan mengurangi nyeri (Meliana Sitinjak et al., 2016).

\section{SIMPULAN}

Pengabdian masyarakat dapat berjalan dengan lancar dan tertib di Desa Perigi, Kecamatan Pulau Pinang, Kabupaten Lahat yang merupakan wilayah kerja dari Puskesmas Pulau Pinang. Hasil dari intervensi menunjukan adanya penurunan skala nyeri pada penderita rheumatoid arthritis setelah diberikan intervensi senam rematik. Diharapkan Senam rematik dapat berlanjut menjadi kegaiatan latihan fisik rutin di wilayah kerja Puskesmas Pulau Pinang.

\section{UCAPAN TERIMA KASIH}

Penulis mengucapkan terima kasih kepada Poltekkes Kemenkes Palembang yang telah memberi dukungan financial terhadap pengabdian ini. Tak lupa kami mengucapkan terima kasih kepada Kepala Puskesmas Pulau Pinang, tenaga kesehatan, tokoh masyarakat, dan kader kesehatan di Desa Perigi yang telah membantu dan memfasilitasi proses kegiatan ini, sehingga dapat berjalan dengan baik dan lancar.

\section{DAFTAR RUJUKAN}

Afnuhazi, R. (2018). Pengaruh senam rematik terhadap penurunan nyeri rematik pada lansia. Menara IImu, XII(79), 118.

Arfitasari, B. (2020). Pengaruh Pemberian Pelatihan Senam Rematik Terhadap Penurunan Intensitas Nyeri Pada Penderita Rheumatoid Arthtritis di Desa Mancasan Kec. Baki Kab. Sukoharjo. Artikel Penelitian, 1(1), 1-21.

CDCV. (2020). Rheumatoid Arthritis (RA). https://www.cdc.gov/arthritis/basics/rheu matoid-arthritis.html

HERI KUSWANTO. (2014). PENGARUH SENAM REMATIK TERHADAP NYERI SENDI PADA LANSIA DI PANTI SOSIAL TRESNA WERDHA BUDIMULIA 04 MARGAGUNA JAKARTA SELATAN. https://digilib.esaunggul.ac.id/pengaruhsenam-rematik-terhadap-nyeri-sendipada-lansia-di-panti-sosial-tresnawerdha-budimulia-04-margagunajakartaselatan-3177.html

Intermountein Healthcare. (2016). Why Women Get More Arthritis Than Men. https://intermountainhealthcare.org/blogs/ topics/live-well/2016/05/womens-arthritis/

Meliana Sitinjak, V., Fudji Hastuti, M., \& Nurfianti, A. (2016). Pengaruh Senam Rematik terhadap Perubahan Skala Nyeri pada Lanjut Usia dengan Osteoarthritis Lutut. Jurnal Keperawatan Padjadjaran, v4(n2), 139-150. https://doi.org/10.24198/jkp.v4n2.4

RISKESDAS. Laporan_Nasional_RKD2018_FINAL.pdf. In Riskesdas (p. 198). Kementerian Kesehatan Republik Indonesia. http://labdata.litbang.kemkes.go.id/image s/download/laporan/RKD/2018/Laporan_ Nasional_RKD2018_FINAL.pdf

Safiri, S., Kolāhi, A. A., Hoy, D., Smith, E., Bettampadi, D., Mansournia, M. A., Almasi-Hashiani, A., Ashrafi-Asgarabad, A., Moradi-Lakeh, M., Qorbani, M., Collins, G., Woolf, A. D., March, L., \& Cross, M. (2019). Global, regional and national burden of rheumatoid arthritis 1990-2017: a systematic analysis of the Global Burden of Disease study 2017. Annals of the Rheumatic Diseases, 78(11), 1463-1471. https://doi.org/10.1136/annrheumdis2019-215920

Siahaan, P., Siagian, N., \& Elon, Y. (2017). Efektivitas Pijat Punggung Terhadap Intensitas Nyeri Rematik Sedang Pada Wanita Lanjut Usia Di Desa Karyawangi Kabupaten Bandung Barat. Jurnal Skolastik Keperawatan, 3(1), 53. https://doi.org/10.35974/jsk.v3i1.580

Siebert, S., Lyall, D. M., MacKay, D. F., Porter, D., Mclnnes, I. B., Sattar, N., \& Pell, J. P. (2016). Characteristics of rheumatoid arthritis and its association with major comorbid conditions: Cross-sectional study of 502649 UK Biobank participants. RMD Open, 2(1). https://doi.org/10.1136/rmdopen-2016000267

Susilowati, T. (2016). Senam Rematik Meningkatkan Jarak Tempuh Berjalan Lansia dengan Nyeri Sendi di Panti Wreda 
Dharma Bhakti Pajang Surakarta. Jurnal Ners Dan Kebidanan (Journal of Ners and Midwifery), $\quad 3(3), \quad 328-334$. https://doi.org/10.26699/jnk.v3i3.art.p328334

Walsh, D. A., \& McWilliams, D. F. (2014). Mechanisms, impact and management of pain in rheumatoid arthritis. Nature Reviews Rheumatology, 10(10), 581-592. https://doi.org/10.1038/nrrheum.2014.64 